\title{
Consciousness of Dairy Farmers about Rabies an Oldest Zoonosis
}

\author{
S.J. Jadav ${ }^{1}$, J.K. Patel ${ }^{2}$
}

10.18805/ajdfr.DR-1821

\begin{abstract}
Background: The study was carried out to assess the consciousness of dairy farmers about rabies as an oldest zoonosis. Methods: Using the simple random sampling method, 180 dairy farmers from 36 villages of 6 talukas of Panchmahals and Mahisagar districts of Gujarat state (India) were selected.

Result: The majority of dairy farmers $(90.56 \%)$ had high to very high level of consciousness about rabies. The majority of dairy farmers had medium to high level of knowledge $(72.22 \%)$, high to very high level of sensitivity $(91.11 \%)$ and favorable to most favorable attitude $(95.55 \%)$ towards the control of rabies. Path analysis show the maximum positive direct effect had exerted by scientific orientation and mass media exposure and age exerted maximum negative direct effect. Economic motivation and extension participation exerted maximum indirect positive effects. Dairy farmers can enhance their consciousness about rabies through participation in different extension activities with using mass media, internet and other psychological variables. The findings of this study would serve as a guideline for researchers, training institutions, planners, extension agencies and concerned organizations in the formation of effective realistic training programmes to impart consciousness amongst the dairy farmers about rabies and other zoonoses.
\end{abstract}

Key words: Attitude, Consciousness, Dairy farmers, Knowledge, Rabies, Sensitivity, Zoonosis.

\section{INTRODUCTION}

Rabies is one of the ancients documented diseases of humankind. Lyssavirus causes classic rabies come under the family Rhabdoviridae and had 2-3 months incubation period but may vary from 1 week to 1 year, dependent upon factors like viral load, location of virus entry, etc. There are around 59,000 human deaths annually in over 150 countries due to rabies with 95 per cent of cases occurring in Africa and Asia (WHO, 2018). India accounts for 35 per cent of rabies deaths globally. India has the world's highest number of dog-bite related to rabies deaths, most of whom are people of low socio-economic background from rural areas (Acharya et al. 2012). A lack of awareness about rabies in rural India is one of the factors that lead to high human mortality from rabies (Sudarshan et al. 2007). Dogs are the leading source of human rabies deaths, which are contributing up to 99 per cent of all human rabies. Worldwide, rabies causes an estimated cost of US $\$ 8.6$ billion per year.

This obviously implies that dairy farmers must be educated to acquire higher level of consciousness and technical skills to prevent and control of rabies to avoid economic losses as well as animal and human health hazards. One way extension scientists can contribute to this task to find out better ways and means for promoting the consciousness about rabies among the clientele group. Since the change in knowledge and attitude precede sensitivity in preventing and controlling rabies, it is always important to find out the most influential factors of changing farmers' knowledge about rabies, molding positivism towards its control and their sensitivity. Unfortunately this type of research has not been conducted in the study area. The study will be helpful to policy makers in developing concrete strategies to prevent and control rabies.
${ }^{1}$ Dairy Vigyan Kendra, SMC College of Dairy Science, Anand Agricultural University, Anand-388 110, Gujarat, India.

${ }^{2}$ Extension Education Institute, Anand Agricultural University, Anand-388 110, Gujarat, India.

Corresponding Author: S.J. Jadav, Dairy Vigyan Kendra, SMC College of Dairy Science, Anand Agricultural University, Anand388 110, Gujarat, India. Email: sanjay.jadav89@gmail.com

How to cite this article: Jadav. S.J. and Patel. J.K. (2022). Consciousness of Dairy Farmers about Rabies an Oldest Zoonosis Asian Journal of Dairy and Food Research. DOI: 10.18805/ ajdfr.DR-1821.

Submitted: 13-10-2021 Accepted: 24-12-2021 Online: 29-01-2022

\section{MATERIALS AND METHODS}

\section{Study area}

The present study was conducted in Panchmahals and Mahisagar districts of Gujarat state (India) between the periods of August to October 2020. Panchmahals district has total of seven talukas (Godhra, Halol, Kalol, Jambughoda, Shehera, Morwa (Hadaf) and Ghoghamba). Panchmahals district lies between 22.45 Northern latitudes and 73.36 Eastern longitudes. Mahisagar district consists of 6 talukas (Balasinor, Lunawada, Kadana, Virpur, Santrampur and Khanpur). Mahisagar district geographically lies between 23.13 Northern latitudes and 73.62 Eastern longitudes.

\section{Study design}

Three talukas each were selected from Panchmahals district and Mahisagar district based on the higher bovine population (Fig 1). Six villages from each taluka were selected randomly. Five dairy farmers were selected from each village randomly. 


\section{Survey instruments}

The independent variables of this research study were measured with the help of appropriate scales used by other researchers with due modification. To measure the consciousness of dairy farmers, a standardized scale was developed by Jadav and Patel, (2021) which is used. Knowledge about rabies and attitude towards control of rabies were measured with the help of scale developed by researcher and sensitivity towards rabies was measured by teacher made scale.

\section{Knowledge, attitude and sensitivity score}

In case of knowledge score aspect, a weightage of 1 was assigned to the correct answer and for an incorrect answer, a weightage of " 0 " was assigned. The possibility to get the knowledge scores ranged from 0 to 16 for an individual. In relation to sensitivity score, the scores of 1 and 0 were assigned for right and wrong response attributed by a dairy farmer, respectively. There were a total of six sensitivity statements for rabies. For the attitude score aspect, out of the 12 selected statements, eleven statements were positive and had indicators of favorable attitude and one statement was negative and had unfavorable attitude. Items related to attitude were measured on a Likert scale ranging from 1 to 5 (1 = strongly disagree to $5=$ strongly agree), with higher scores indicating the most desired attitude. The possibility to get the attitude scores ranged from 12 to 60 for an individual. Computation of consciousness index was developed by Jadav and Patel (2021) which is used.

\section{Data analysis}

Respondents were categorized into very low, low, medium, high and very high categories with help of arbitrary method. Coefficient of correlation $(r)$ was calculated to find out the relationship between each of the independent variables and dependent variable. To know the direct and indirect effect of independent factors on the consciousness of dairy farmers about rabies, the method of path co-efficient analysis (Wright, 1921) was employed. The data were collected with the help of pre-tested Gujarati version interview schedule by personal interview and then after it was compiled, tabulated and analyzed to get a proper answer for the specific objectives of the study with the help of various appropriate statistical tools. SPSS 21 (IBM, USA) was used to process the collected data.

\section{RESULTS AND DISCUSSION}

The mean percentage score for knowledge was 62.26 (SD: 16.68). It can be observed in Table 1 that more than half $(56.11 \%)$ of the dairy farmers had knowledge that dog and cats are the source of rabies. A similar finding was reported by Digafe et al. (2015) and Dabuma et al. (2017). There were only 45.00 per cent of the dairy farmers gave correct answer on the question "is there any specific treatment for rabid animals?" and remaining 55.00 per cent of them believed that it is treatable. A study conducted in Ethiopia by Digafe et al. (2015) who reported that 27.8 per cent of the respondents believed that rabies is a treatable disease.

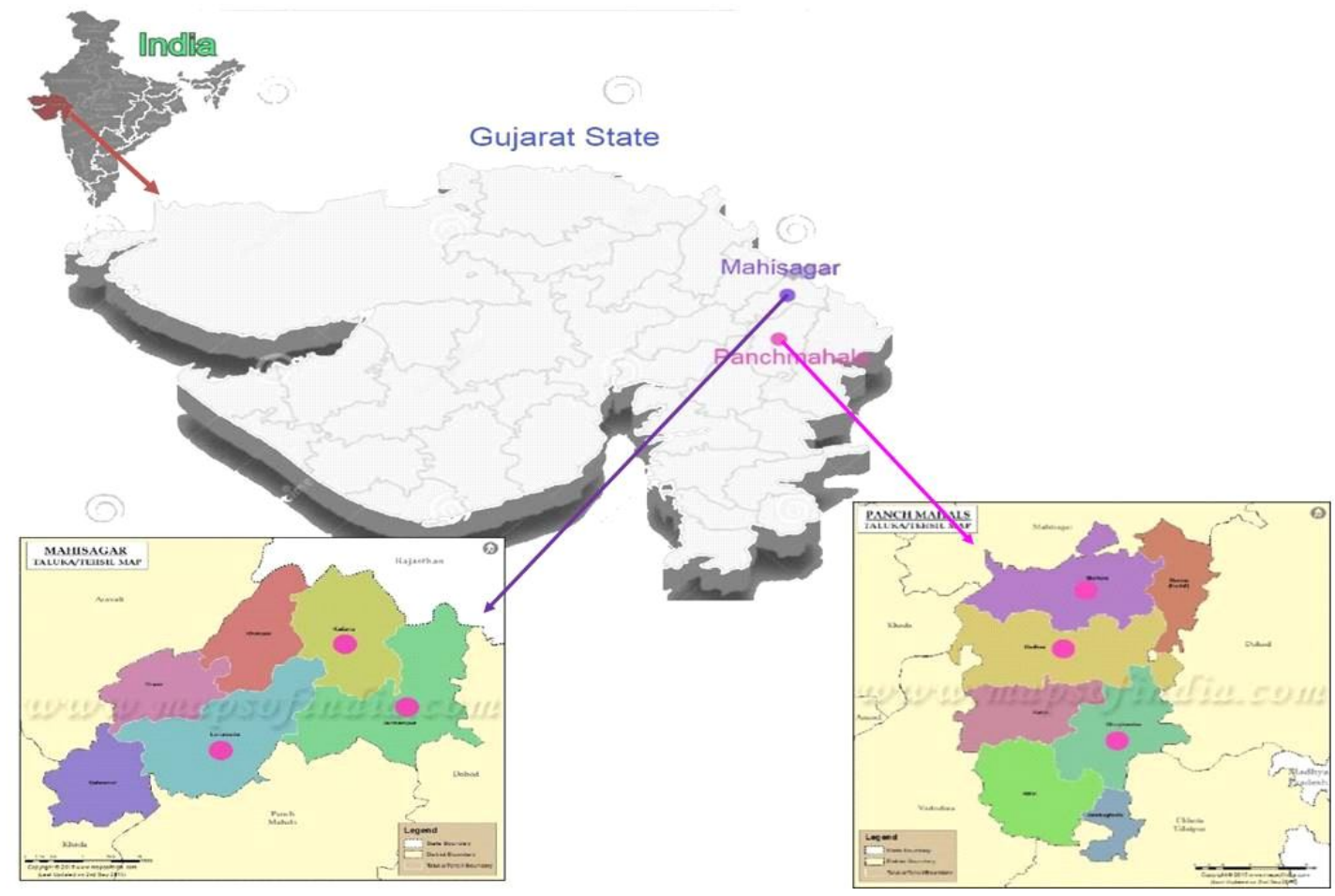

Fig 1: Map of Panchmahals district and Mahisagar district showing the selected talukas. 
Majority of the dairy farmers $(92.22 \%)$ had knew about transmission of rabies through ingestion of contaminated food, meat or milk. More than half of the dairy farmers knew about the symptoms of rabies in animal and human. Majority of the dairy farmers had knew about prevention of rabies through post bite vaccination and washing the dog bite site with soap and running water. There are two surprising findings; one is that more than two-thirds $(66.67 \%)$ of the dairy farmers had believed that red chili powder helps to cure rabies and the second is more than one-third $(38.89 \%)$ of them believed in bhuva-dhaga or superstition for curing the rabies in animals. A similar finding was observed by Singh and Choudhary, (2005) indicated that 19.20 per cent were the believer of some religious customs such as chilli application or tobacco leaf application or tie a bell to Hadakwa Mata temple and others. There is a belief of dairy farmers about rabies that it can be treatable. This will be the most challenging task for

Table 1: Knowledge, sensitivity and attitude level of dairy farmers about rabies $(n=180)$.

\begin{tabular}{|c|c|c|}
\hline Sr.No. & Statements & No. $(\%)$ of respondents \\
\hline & Knowledge statements & \\
\hline I & General information of disease & \\
\hline 1 & Dog \& cats are the source of rabies. & $101(56.11)$ \\
\hline 2 & Any specific treatment for rabid animals. (-) & $81(45.00)$ \\
\hline II & Transmission route & \\
\hline 3 & Rabies can transmit through ingestion of contaminated food, meat, or milk. & $166(92.22)$ \\
\hline 4 & Rabies can transmit via contamination of skin wounds by fresh saliva of rabid animals. & $83(46.11)$ \\
\hline 5 & A rabid animal's scratch can be infected. & $153(85.00)$ \\
\hline III & Symptoms of animal (suffering from rabies) & \\
\hline 6 & Aggressiveness, difficult in swallowing \& cease to ruminate and excessive salivation & $132(73.33)$ \\
\hline 7 & Hydrophobia and bellowing & $94(52.22)$ \\
\hline 8 & Paralysis of muscles, low milk production and bite to other animal or human & $98(54.44)$ \\
\hline IV & Symptoms of human (suffering from rabies) & \\
\hline 9 & Aggressiveness, increase salivation and hydrophobia & $126(70.00)$ \\
\hline 10 & Photophobia, difficulty in swallowing and paralysis & $121(67.22)$ \\
\hline $\mathbf{V}$ & Prevention \& control aspects & \\
\hline 11 & Post-bite vaccination can able to prevent rabies in humans. & $129(71.67)$ \\
\hline 12 & Superstition (bhuva-dhaga) can help to cure rabies in animals. (-) & $110(61.11)$ \\
\hline 13 & Avoiding contact with bats is able to prevent rabies. & $86(47.78)$ \\
\hline 14 & Red chili powder helps to cure rabies. (-) & $60(33.33)$ \\
\hline 15 & Washing the dog bite site with soap and running water can help to prevent rabies. & $155(86.11)$ \\
\hline \multirow[t]{2}{*}{16} & Suturing the dog bite site to control the spread of rabies virus. $(-)$ & $98(54.44)$ \\
\hline & Sensitivity statements & \\
\hline 1 & Sensitive regarding the impact of rabies on humans. & $177(98.33)$ \\
\hline 2 & Sensitive regarding animal vaccination for rabies. & $172(95.56)$ \\
\hline 3 & Sensitive to avoid the movement of stray dogs near your animals. & $153(85.00)$ \\
\hline 4 & Sensitive towards the control of the stray dog population in your village. & $155(86.11)$ \\
\hline 5 & Sensitive regarding washing dog bite site with soap and running water. & $164(91.11)$ \\
\hline \multirow[t]{2}{*}{6} & Sensitive to put chilli powder at dog bite site. (-) & $57(31.67)$ \\
\hline & Attitude towards control of rabies & Mean percent score \\
\hline 1 & I believe that vaccination is the right way to prevent rabies. & 82.33 \\
\hline 2 & I believe that rabies can be eradicated from our country. & 80.44 \\
\hline 3 & I feel that rabies is hazardous to human health. & 84.44 \\
\hline 4 & There is a lot of propaganda about rabies, but it is not so in a real situation. & 73.56 \\
\hline 5 & I would like to purchase rabies-free animals for my farm. & 79.89 \\
\hline 6 & I believe that rabies is the current burning issue to handle seriously. & 73.00 \\
\hline 7 & I believe that the sale of animals infected with rabies is ethical. (-) & 64.22 \\
\hline 8 & I feel that constant monitoring is needed to control rabies. & 79.89 \\
\hline 9 & Rabies-infected animals affect badly dairy farm income. & 81.78 \\
\hline 10 & I believe that rabies can be successfully controlled through managemental practices. & 80.22 \\
\hline 11 & I feel that control of rabies should be a prime goal of veterinary public health. & 80.00 \\
\hline 12 & I believe that public awareness regarding rabies is the need of hours. & 81.44 \\
\hline
\end{tabular}

$(-)$ indicate the negative question asked to respondents. 
veterinary public health and veterinary extension functionary to convince them that the disease is totally fatal and non-treatable after the manifestation of clinical symptoms. Majority of the dairy farmers had sensitive towards the impact of rabies on human health, vaccination, washing dog bite site with soap and running water and avoid and control of stray dog population. The mean percentage score for sensitivity was 81.30 (SD: 14.06). Majority of the dairy farmers had positive attitude towards the control of rabies like vaccination (82.33 Mean Percent Score), awareness (81.44 MPS) and constant monitoring (79.89 MPS). Most of the dairy farmers felt that rabies is hazardous to human health (84.44 MPS). A similar finding was observed by Abdela et al. (2017) and reported that majority of the respondents $(80.0 \%)$ considered rabies as a fatal disease. Majority of the dairy farmers (80.22 MPS) believed that rabies can be successfully controlled through managemental practices. A contrary finding was observed by Abdela et al. (2017) and reported that more than twothird of the participant do not believed that rabies not to be prevented by vaccination and eliminating stray dog like managmental practices. Perceived human health hazards effect of rabies as a zoonotic disease on animals and human beings by the dairy farmers as well as economic losses caused by such a disease was the major reasons for the formation of positivism toward control of rabies might be the possible explanation for this result. The mean percentage score for attitude was 78.44 (SD: 9.30). The detailed analysis of knowledge, sensitivity and attitude of dairy farmers towards prevent and control of rabies is described in Table 1.

The majority $(72.22 \%)$ of dairy farmers fall under medium to high level of knowledge about rabies (Table 2 and Fig 2). This might be due to that rabies is one of the oldest and fatal diseases as known by dairy farmers. These findings were in accordance with Tiwari et al. (2019) who reported that majority of the dairy farmers was well known about rabies. The vast majority $(91.11 \%)$ of dairy farmers had high to very high sensitivity towards rabies. This is because of the majority of dairy farmers were known about effect of rabies on animal and human health. A similar finding was reported by Munisamy et al. (2017). A vast majority $(95.55 \%)$ of the dairy farmers had favorable to most favorable attitude towards control of rabies. A similar finding was observed by Bagherian et al. (2018) and reported that almost all $(91 \%)$ of respondents categorized as good attitude regarding animal bite and rabies.

The majority $(67.78 \%)$ of dairy farmers had high level of consciousness about rabies, followed by 22.78 per cent very high level of consciousness (Table 3 ). Knowledge of the dairy farmers about rabies (especially on prevention and control aspect) as a component of consciousness is still to work for enhancing consciousness level of dairy farmers regarding rabies as a zoonosis. Costa and Fernandes, (2016) indicated a clear need to increase public

Table 2: Knowledge, sensitivity and attitude level of dairy farmers about rabies $(n=180)$.

\begin{tabular}{lcc}
\hline & Frequency & Per cent \\
\hline Knowledge category & 1 & 0.56 \\
Very low (up to 20.00 per cent) & 18 & 10.00 \\
Low (20.01 to 40.00 per cent) & 58 & 32.22 \\
Medium (40.01 to 60.00 per cent) & 72 & 40.00 \\
High (60.01 to 80.00 per cent) & 31 & 17.22 \\
Very high (above 80.00 per cent) & 180 & 100.00 \\
Total & & \\
Sensitivity category & 0 & 0.00 \\
Very low (up to 20.00 per cent) & 2 & 1.11 \\
Low (20.01 to 40.00 per cent) & 14 & 7.78 \\
Medium (40.01 to 60.00 per cent) & 22 & 12.22 \\
High (60.01 to 80.00 per cent) & 142 & 78.89 \\
Very high (above 80.00 per cent) & 180 & 100.00 \\
Total & & \\
Attitude category & 0 & 0.00 \\
Most unfavorable (up to 20.00 per cent) & 0 & 0.00 \\
Unfavorable (20.01 to 40.00 per cent) & 8 & 4.45 \\
Neutral (40.01 to 60.00 per cent) & 105 & 58.33 \\
Favorable (60.01 to 80.00 per cent) & 67 & 37.22 \\
Most favorable (above 80.00 per cent) & 180 & 100.00 \\
Total & & \\
\hline
\end{tabular}

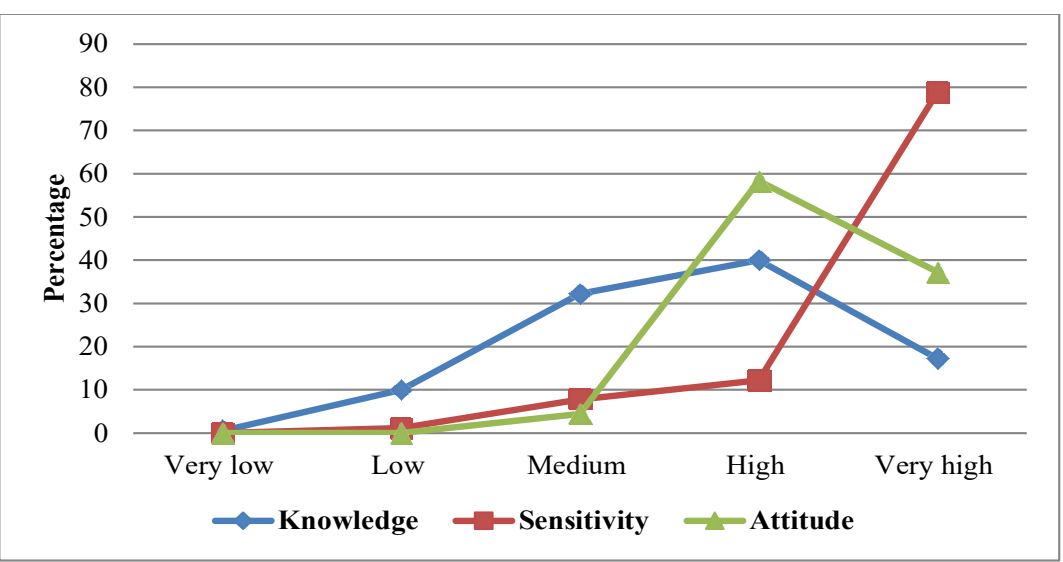

Fig 2: Knowledge, sensitivity and attitude level of dairy farmers about rabies. 
Table 3: Dairy farmers according to their consciousness about rabies $(n=180)$

\begin{tabular}{lcc}
\hline Category & Frequency & Per cent \\
\hline Very low (up to 20.00 per cent) & 0 & 0.00 \\
Low (20.01 to 40.00 per cent) & 1 & 0.55 \\
Medium (40.01 to 60.00 per cent) & 16 & 8.89 \\
High (60.01 to 80.00 per cent) & 122 & 67.78 \\
Very high (above 80.00 per cent) & 41 & 22.78 \\
Total & 180 & 100.00 \\
\hline
\end{tabular}

consciousness with regard to the potential risk of rabies and the means of avoiding the disease, through educational initiatives directed at the local population. In line with our report, Singh and Choudhary, (2005) indicated that 98.60 per cent of people from a rural community of Gujarat, India were aware about rabies and also by Abdela et al. (2017) and Dabuma et al. (2017) who reported that the overall KAP scores were good implying that the communities had good awareness about rabies.

The Pearson correlation analysis was conducted to identify the relationship between factors affecting the consciousness of dairy farmers about rabies and independent variables. In Fig 3 , out of fifteen independent variables, nine variables had established a positive and significant relationship with the consciousness of dairy farmers about rabies. The result shows that the consciousness of dairy farmers about rabies was significantly increasing with increase in education, participation in extension activities and training programmes, exposure of mass media and internet with scientific orientation and economic motivation. Correlation between knowledge level with sensitivity level (0.256) and attitude level (0.420) and sensitivity with attitude (0.225) of dairy farmers regarding rabies was found to be positive and significance at 1 per cent. This is in agreement with study by Costa and Fernandes, (2016) who reported that the education of individual had a significant influence on their knowledge of rabies but not by age.

\section{Path analysis - direct effect}

The data in Fig 4 revealed that major variables contributing the maximum direct positive effect on the consciousness of rabies were scientific orientation (0.3900), mass media exposure (0.2908), family size, dairy farming experience, professional training received, social participation, internet exposure, economic motivation, annual income and extension participation in descending order.

\section{Path analysis - total indirect effect}

Fourteen variables had a positive total indirect effect out of fifteen on the consciousness of dairy farmers about rabies. Further, it can be observed that economic motivation had maximum total indirect effect $(0.3871)$ through substantial indirect effect-1 [scientific orientation (0.2621)] and substantial indirect effect-2 [mass media exposure (0.1096)].

\section{Path analysis - substantial indirect effect}

Data further revealed that out of 30 substantial indirect effects, thirteen routed through scientific orientation and

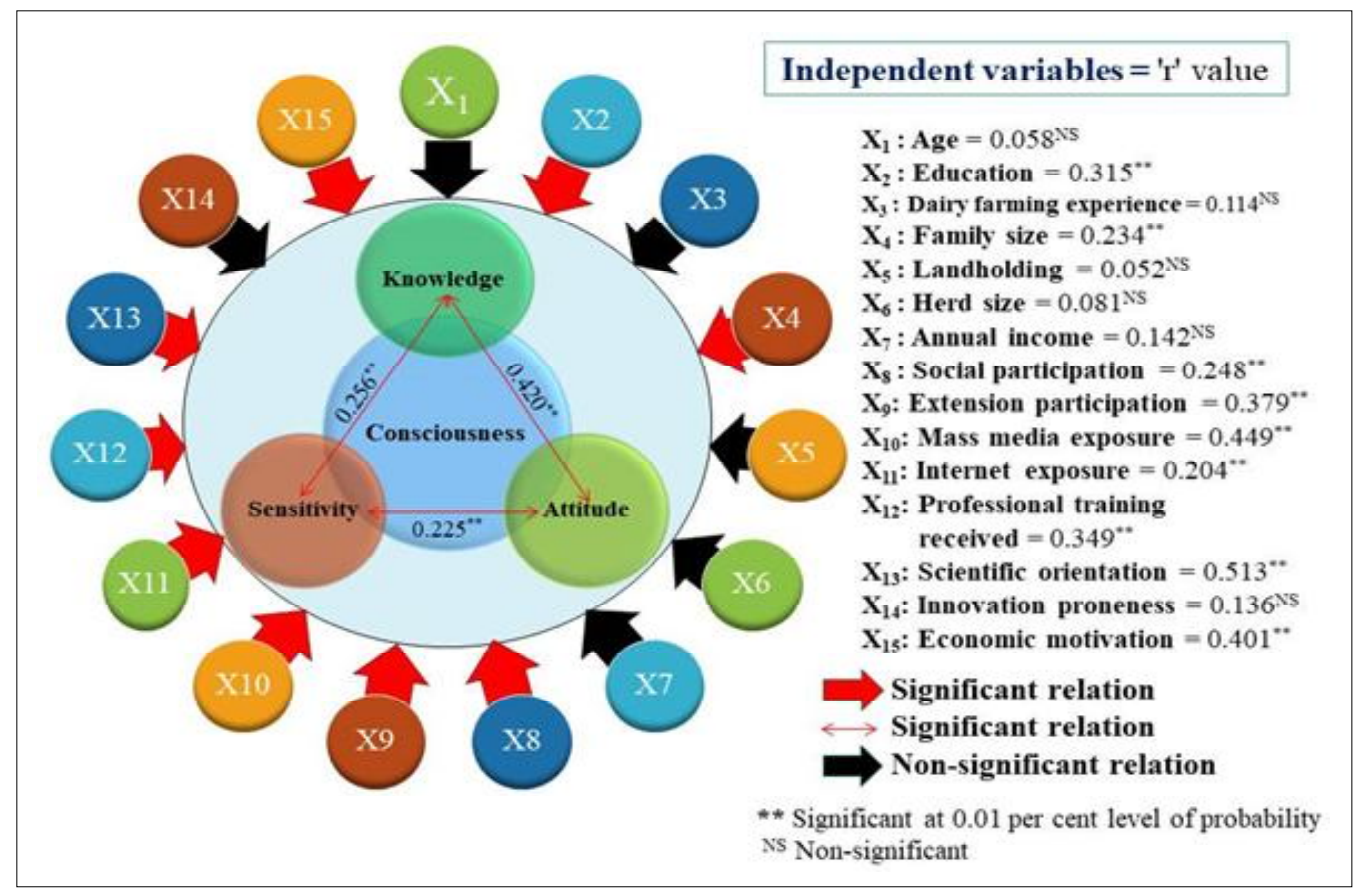

Fig 3: An empirical model shows the cause of independent variables on consciousness of dairy farmers about rabies. 


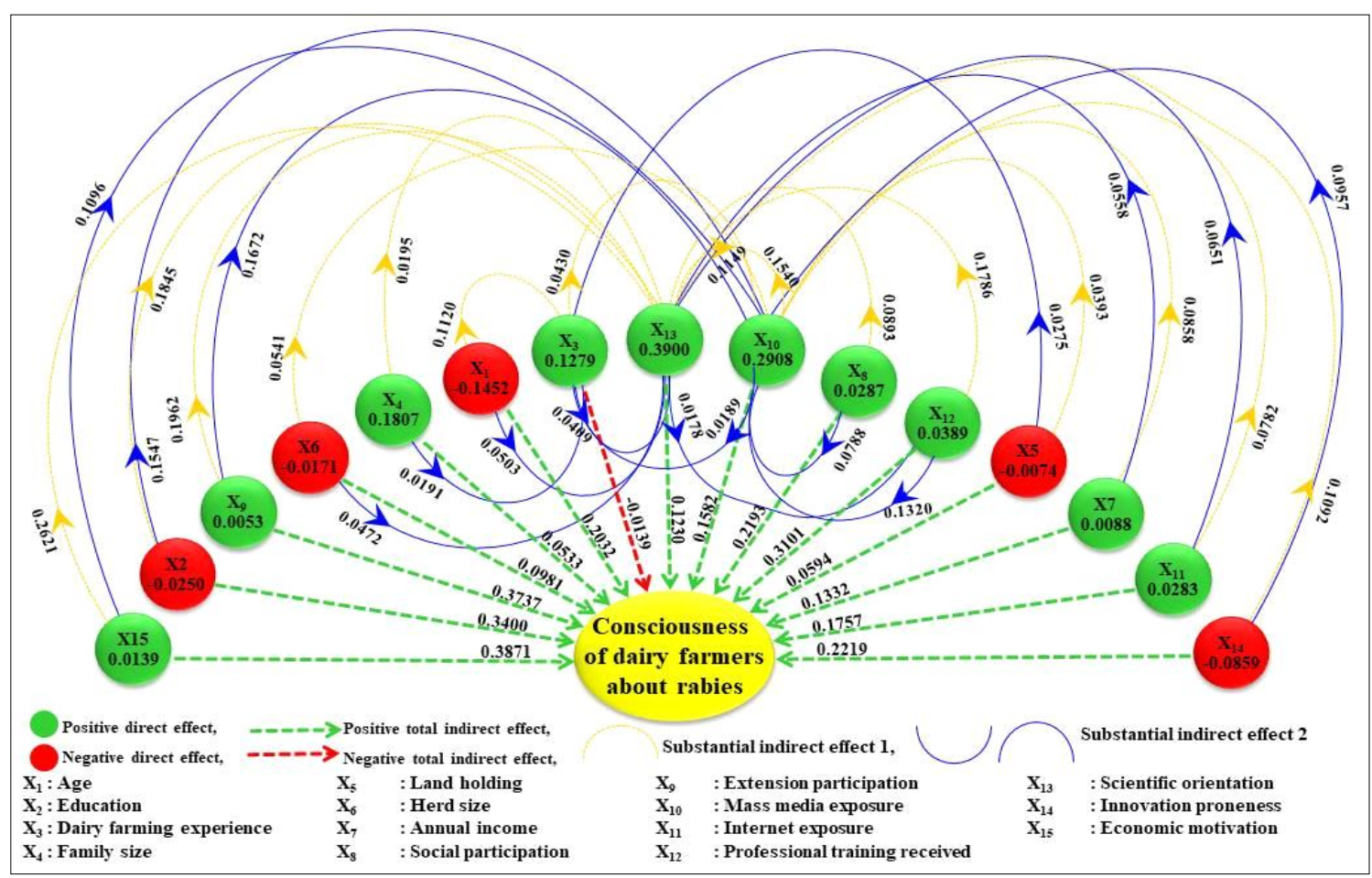

Fig 4: Path diagram of direct and indirect effect of independent variables on consciousness of dairy farmers about rabies.

twelve routed through mass media exposure, four routed through education and one routed through professional training received.

To epitomize the result, it can be concluded that scientific orientation and mass media exposure of dairy farmers was the key variables in exerting considerable direct and substantial effect for determination of consciousness of rabies, whereas economic motivation, extension participation, education and training had exerted the higher indirect effect on the consciousness of dairy farmers about rabies which are seen in Fig 4.

\section{CONCLUSION}

There is a need to organize special programmes to improve the knowledge (especially on prevention and control aspect) on rabies as zoonosis to enhance the consciousness of dairy farmers and general people about rabies. Path analysis show that scientific orientation, mass media exposure, economic motivation, extension participation and education which had established significant effect (direct or indirect) on the consciousness of dairy farmers about rabies as a zoonosis must be reckoned while planning any programme related to zoonoses.

\section{REFERENCES}

Abdela, N., Midekso, B., Jabir, J. and Abdela, W. (2017). Knowledge, attitudes and practices towards rabies in Dedo district of Jimma zone, southwestern Ethiopia: A community based cross-sectional study. International Journal of Medicine and Medical Sciences. 9(5): 61-71.
Acharya, A.S., Ravneet, K. and Kulwant, L. (2012). Rabies epidemiology and control in India: A review. Journal of Communicable Diseases. 44(2): 59-69.

Bagherian, H.R., Taghipour, A., Bazaz, M.M., Nezamdoost, F., Afshari, R. and Abedi, F. (2018). Knowledge, Attitudes and Practices Regarding Animal Bites and Rabies; a Multi-Centre Study. Asia Pacific Journal of Medical Toxicology. 7: 92-95.

Costa, L.J.Cd. and Fernandes, M.E.B. (2016). Rabies: Knowledge and Practices Regarding Rabies in Rural Communities of the Brazilian Amazon Basin. PLOS Neglected Tropical Diseases. 10(2): e0004474.

Dabuma, T., Kabeta, T. and Mengist, H.M. (2017). Assessment of Basic Knowledge, Attitude and Practice of Community on Rabies and Retrospective Survey in and around Ambo Town, West Shoa Zone of Ethiopia. Journal of Medical Microbiology and Diagnosis. 6: 263.

Digafe, R.T., Kifelew, L.G. and Mechesso, A.F. (2015). Knowledge, attitudes and practices towards rabies: questionnaire survey in rural household heads of Gondar Zuria District, Ethiopia. BMC Research Notes. 8: 400.

Jadav, S. J. and Patel, J K. (2021). Consciousness of dairy farmers about leptospirosis disease as a zoonosis. Indian Journal of Dairy Science. 74(4): 356-361.

Munisamy, B., Prejit., Sivanathan, P. and Kannan, P. (2017). Knowledge assessment through surveying on cattle zoonotic diseases in dairy farmers. International Journal of Current Microbiology and Applied Sciences. 6(3): 783-794.

Singh, S.U. and Choudhary, S.K. (2005). Knowledge, attitude, behavior and practice study on dog-bites and its management in the context of prevention of rabies in a rural community of Gujarat. Indian Journal of Community Medicine. 30(3): 81-83. 
Sudarshan, M.K., Madhusudana, S.N., Mahendra, B.J., Rao, N.S.N., Narayana, D.H.A., Rahman, S.A., Meslin, F.X., Lobo, D., Ravikumar, K. and Gangaboraiah. (2007). Assessing the burden of human rabies in India: results of a national multi-center epidemiological survey. International Journal of Infectious Diseases. 11(1): 29-35.

Tiwari, H.K., O'Dea, M., Robertson, I.D. and Vanak, A.T. (2019). Knowledge, attitudes and practices (KAP) towards rabies and free-roaming dogs (FRD) in Shirsuphal village in western India: A community based cross-sectional study. PLOS Neglected Tropical Diseases. 13(1): e0007120. World Health Organization, (2018). WHO Expert Consultation on Rabies: Third Report; Abela-Ridder, B., Ed.;World Health Organization: Geneva, Switzerland.

Wrights, S.A. (1921). Correlation and Causation. Journal of Agricultural Research. 20: 557-585. 